\title{
MÍDIAS DIGITAIS NA CONSTRUÇÃO DA IMAGEM DE MARCA: PERSPECTIVAS EXPERIENCIAIS A PARTIR DO MASTERCHEF BRASIL
}

\author{
Digital media in building the brand image: experiential \\ perspectives from MasterChef Brazil
}

\section{La construcción de la imagen de una marca en los medios digitales: experiencias desde MasterChef Brasil}

\author{
Moisés Cardoso \\ Universidade Regional de Blumenau, Santa Catarina, Brasil. \\ Doutorando no Programa de Pós-Graduação em Comunicação e Linguagens da Universidade Tuiuti do Paraná. \\ Mestre em Desenvolvimento Regional, pós-graduado em Novas Mídias. Publicitário e jornalista, professor no curso \\ de Publicidade e Propaganda da Universidade Regional de Blumenau e da Faculdade Metropolitana de Guaramirim. \\ E-mail: beiocardoso@gmail.com
}

\section{Amanda Letícia Assini}

Universidade Regional de Blumenau, Santa Catarina, Brasil.

Bacharel em Comunicação Social do curso de Publicidade e Propaganda da Universidade Regional de Blumenau. E-mail: amandaassini@gmail.com

RESUMO Este artigo aborda o reality show MasterChef Brasil e o uso do microblog Twitter. Tem como objetivo identificar as táticas usadas pelo programa para a construção da imagem de marca. Para sua viabilidade, foi utilizado o método de pesquisa bibliográfico juntamente com o documental, com abordagem qualitativa e posterior estudo de caso do perfil do MasterChef Brasil. A partir deste perfil, puderam-se constatar as táticas utilizadas pelo objeto desta pesquisa e confirmar a eficiência do Twitter enquanto ferramenta de interação entre as marcas e seus fãs, além da compreensão dos aspectos motivacionais de comunicação das empresas nesta rede social, para construção da imagem de marca.

PALAVRAS-CHAVE Mídias digitais, Comunicação, MasterChef Brasil, Marca.

ABSTRACT This article addresses the reality show MasterChef Brazil and the use of Twitter. It aims to identify the tactics used by the show to build the brand image. For its viability, both bibliographic and documentary research methods were used, with a qualitative approach and later case study of the MasterChef Brazil profile. From it, we could verify the tactics used by the research object in question, confirm the effectiveness of Twitter as an interaction tool between the brands and their fans, and understand the motivational aspects of communication of the companies in this social network to build the brand image.

KEYWORDS Digital media, Communication, MasterChef Brazil, Brand.

RESUMEN Este texto aborda el reality show MasterChef Brasil y el uso del microblog Twitter. Su objetivo es identificar las tácticas utilizadas por el programa para construir la imagen de una marca. En el estudio se utilizó el método de investigación bibliográfico con el documental con enfoque cualitativo y posterior estudio de caso del perfil de MasterChef Brasil. Desde este perfil, se pudo observar las tácticas utilizadas por el objeto de investigación y confirmar la eficacia de Twitter como herramienta de interacción entre las marcas y sus aficionados, así como la comprensión de los aspectos motivacionales de la comunicación corporativa en esta red social, en la construcción de la imagen de marca.

PALABRAS CLAVE Medios digitales, Comunicación, MasterChef Brasil, Marca. 


\section{INTRODUÇÃO}

O surgimento da era digital proporcionou a possibilidade de difusão de informações de uma forma rápida e interativa. Nesse contexto, as redes sociais se destacam e possuem grande influência (RECUERO, 2012). Essa fase de digitalização altera consideravelmente as formas de consumo e de relacionamento que os clientes têm com as corporações. As mídias sociais se tornam indispensáveis quando permitem que consumidores influenciem outros com suas opiniões e experiências. Dessa forma, percebemos que seu uso não se limita apenas a divulgar a marca, mas também cria uma relação com os clientes (TELLES, 2010).

O MasterChef Brasil é um exemplo de como as organizações podem se inserir no mundo das mídias sociais. Ele utilizou-se de estratégias de interação e relacionamento com os espectadores durante toda a temporada, tornando-se um exemplo de atuação no Twitter. Enotre os métodos utilizados, é indispensável lembrar que a revelação do resultado da segunda temporada foi anunciado primeiro na rede social e depois na própria televisão. O sucesso do programa no Twitter foi muito expressivo, situação esta que levou a conceituada autora Recuero (2015) a fazer uma análise do reality show utilizando as publicações que continham a tag "MasterChefBrasil" com o software Gephi, constatando que o programa possui uma grande quantidade de fãs e muitos influenciadores.

Nesse contexto, percebeu-se a oportunidade para a exploração e entendimento do uso do Twitter pelo MasterChef Brasil como objetivo na execução desta pesquisa. Os tweets analisados na investigação compreenderam as duas últimas semanas da segunda temporada, somando um total de 218 publicações, coletadas entre os dias 6 e 16 de setembro de 2015. Essas postagens geraram, até o dia 3 de novembro, 77.478 retweets e 154.314 favorites. Foram gerados um milhão de tweets apenas durante o episódio final (RECUERO, 2015).

Ao analisar os estudos realizados a respeito do uso do Twitter e das estratégias de comunicação, é possível identificar mais de 1.750 artigos científicos publicados em revistas indexadas, o que consolida a validade da pesquisa desenvolvida. Destacam-se nessa vertente os estudos de Kim, Lee e Park (2015); Primo (2012); Recuero (2015); Recuero e Zago (2010); Zago e Silva (2014), entre outros.

Acredita-se que essa investigação possa colaborar de certa forma com o desenvolvimento de estratégias comunicacionais dentro da plataforma midiática digital em prol de necessidades mercadológicas, como o caso abordado. Estruturou-se o artigo em cinco seções: Introdução, Marco Teórico, Metodologia, Apresentação e Discussão dos Resultados, e Considerações Finais.

\section{MARCO TEÓRICO}

\section{Internet, mídias sociais e sua influência no consumo}

Por meio das redes sociais, dos e-commerces e diversas outras plataformas digitais, os usuários têm acesso a tudo literalmente na palma de suas mãos. É possível fazer compras, pagar contas, chamar táxis, conferir as notícias do mundo e conversar com os próximos não apenas utilizando computadores, mas também através dos dispositivos móveis, como smartphones e tablets. 
Além de alterar os hábitos de compra dos bens materiais, a internet também modificou as formas de transmitir informações. Dalmonte (2015) apresenta três modalidades de consumo: partilhado, individualizado, privado e compartilhado. Na última fase, o autor afirma que o consumo de informação se dá de forma privada, porém, segue-se do compartilhamento de opiniões em sites de redes sociais. Ou seja, os usuários estão sempre compartilhando o que pensam e desejam, bem como seus apontamentos sobre diversas questões com pessoas com as quais possuem algum tipo de conexão.

Outra forma de comunicação expressiva no universo on-line que influencia os hábitos de compra é o boca a boca eletrônico, que pode servir para convencer e influenciar o comportamento do consumidor (LARANJEIRA; CARDOSO; KUMM, 2016), em que usuários disseminam as informações no meio digital. Quanto mais se ouve a respeito de algo por parte de pessoas conhecidas e de confiança, maior é a probabilidade de compra ou aceitação da ideia (TERRA, 2011). O grande desafio para as marcas é realmente estar presente em pelo menos alguns dos micromomentos da rotina desse novo consumidor que está sempre conectado. É entender cada vez mais sobre o perfil de cada um e ser o mais relevante possível para conseguir oferecer alguma utilidade ou entretenimento no momento mais adequado (ARRUDA, 2015).

Telles (2010) chama atenção para algumas regras que as corporações devem seguir quando inseridas no meio digital. O autor lembra que não é possível controlar as conversações, mas é possível influenciá-las, e que é indispensável permitir que elas aconteçam, construir relacionamentos e responder às dúvidas dos clientes com honestidade. Essas regras nos mostram como o ambiente das mídias digitais prioriza e dá importância às conversações e interações entre os atores.

As táticas utilizadas pelas empresas só apresentam resultados quando utilizadas com boas estratégias, planejamento e pensamento humano. $\mathrm{Ou}$ seja, assim como os outros meios, a internet e as mídias sociais também requerem cuidados em seu uso (TELLES, 2010). As formas de compra e comunicação on-line são muito expressivas e entendemos que tendem a continuar crescendo. Dessa forma, é ideal que as empresas estejam cientes de sua importância e invistam no espaço virtual.

\section{METODOLOGIA}

Para investigar a eficiência do Twitter enquanto ferramenta para a construção da imagem de marca, utilizou-se o método de pesquisa de natureza básica, exploratória, com abordagem qualitativa e estudo de caso do perfil do MasterChef Brasil no Twitter.

Quanto aos procedimentos técnicos, o trabalho é referente a uma investigação documental juntamente com a bibliográfica a acerca dos temas: internet, mídias sociais e sua influência no consumo.

Durante o período analisado, que compreende os 11 dias entre 6 a 16 de setembro de 2015, foram enviadas 218 publicações pelo perfil do MasterChef Brasil. Estas, por sua vez, geraram 77.478 retweets e 154.314 favorites dos seguidores. A observação das características dessas postagens possibilitou a análise e a compreensão das táticas usadas pelo MasterChef Brasil para divulgar o programa no site de rede social Twitter.

Para realização da análise, foi feita a adaptação do construto metodológico cientifico elaborado por Nunomura (2013) para a realidade do atual objeto de estudo. Vale destacar que esse novo rearranjo do 
construto científico não é validado pelo autor. A pesquisa original, de título "A imprensa, o Twitter e as eleições de 2010 no Brasil”, teve como objetivo examinar o noticiário político e o Twitter, utilizando como estudo de caso as eleições presidenciais no Brasil em 2010. O trabalho discute se a rede social proporcionou aos eleitores novos meios de se comunicar sobre a política. $\mathrm{O}$ autor focou sua análise sobre os trending topics do Brasil, constatando os temas mais populares na campanha e comparou os dados observados com as principais notícias políticas divulgadas pelo jornal Folha de S.Paulo e pela revista Veja, tendo como objetivo conferir a hipótese de agenda-setting no contexto das redes sociais.

O primeiro passo da pesquisa do autor foi analisar a frequência com que a campanha eleitoral atingiu o status de trending topics Brasil (TTBr). Depois, foi feita a coleta de dados no site TTBr.info, somando 280 TTBrs e extraindo apenas os com conotação política, chegando ao total de 93. Em seguida, foi feita a organização do material nas categorias Pró-Dilma, Pró-Serra e Neutro.

Nesse sentido, esta pesquisa reconfigura o construto original para obter diferentes olhares sobre os dados da amostragem. Sendo assim, as publicações foram divididas em categorias, conforme seu conteúdo:

a) tweets que citam marcas: nesta divisão estão as postagens que mencionam as marcas parceiras do programa, através da função "menção" e das hashtags do Twitter;

b) tweets que citam participantes: nesta categoria estão incluídos os tweets que citam os participantes, também através de menções e hashtags;

c) tweets que utilizam a \#MasterChefBR: as publicações que compõem esta categoria são aquelas que utilizam a hashtag MasterChefBR;

d) tweets que utilizam a \#MasterChefResponde: nesta categoria, estão os tweets marcados com a hashtag MasterChefResponde, utilizada pelos usuários para fazer perguntas para a participante Jiang, que as respondeu no perfil do programa;

e) tweets que convidam os seguidores da conta a interagirem com a página: esta categoria abrange as publicações que instigavam os seguidores do perfil do MasterChef a interagirem, através de retweets, hashtags ou menções.

A partir das informações listadas, podem-se compreender os métodos de pesquisa utilizados para a execução deste estudo. Considerando a presença de fatores externos, foi necessário tanto um estudo separado de cada categoria quanto um comparativo entre cada uma delas.

\section{APRESENTAÇÃO E DISCUSSÃO DOS RESULTADOS}

Esta seção dedica-se à análise das categorias, possibilitando entendimento da forma como a pesquisa foi construída. É importante ressaltar que, como as divisões foram pensadas analisando vários aspectos da comunicação e dos tweets, uma publicação pode pertencer a várias categorias. As divisões foram alinhadas conforme a quantidade de tweets enquadrados em suas características. No quadro a seguir, podemos conferir quantas publicações foram incluídas em cada uma dos conjuntos e quantas interações cada uma gerou no total, conforme o Quadro 1.

Analisando as postagens da página, no Quadro 2, podemos avaliar também que, durante o período de estudo, o dia em que a conta apresentou mais atividade foi o dia após a semifinal, 9 de setembro. 
Quadro 1. Enumeração das categorias e interações geradas.

\begin{tabular}{|lccc|}
\hline \multicolumn{1}{|c}{ Categoria } & N. ${ }^{-}$de Tweets & Retweets & Favorites \\
\hline \#MasterChefBR & 136 & 58.950 & 105.400 \\
\hline Participantes & 87 & 52.988 & 90.451 \\
\hline Marcas & 85 & 47.747 & 77.708 \\
\hline Convidam à interação & 58 & 8.096 & 26.105 \\
\hline \#MasterChefResponde & 41 & 8.584 & 16.439 \\
\hline
\end{tabular}

Fonte: Dados elaborados pelos autores (2015).

Quadro 2. Enumeração de dias, tweets gerados e suas respectivas interações.

\begin{tabular}{|lccc|}
\hline \multicolumn{1}{c}{ Dia } & Tweets & RT's & Favorites \\
\hline 6 de setembro & 3 & 62 & 388 \\
\hline 7 de setembro & 7 & 225 & 1.164 \\
\hline 8 de setembro & 37 & 5.474 & 15.569 \\
\hline 9 de setembro & 60 & 9.709 & 20.631 \\
\hline 10 de setembro & 13 & 212 & 1.203 \\
\hline 11 de setembro & 9 & 261 & 1.190 \\
\hline 12 de setembro & 5 & 204 & 895 \\
\hline 13 de setembro & 6 & 330 & 1.076 \\
\hline 14 de setembro & 8 & 559 & 1.794 \\
\hline 15 de setembro & 54 & 12.612 & 37.026 \\
\hline 16 de setembro & 16 & 47.830 & 73.578 \\
\hline Total & $\mathbf{2 1 8}$ & $\mathbf{7 7 . 4 7 8}$ & $\mathbf{1 5 4 . 3 1 4}$ \\
\hline
\end{tabular}

Fonte: Dados elaborados pelos autores (2015).

O Quadro 2 também indica que, apesar de 9 de setembro ter sido o dia que mais contabilizou tweets, a data que gerou mais interações entre retweets e favorites foi o dia depois da final, 16 de setembro. A seguir, é exposta a análise de cada categoria e suas peculiaridades, para maior compreensão da pesquisa.

\section{\#MasterChefBR}

A hashtag MasterChefBR foi utilizada tanto pelo próprio perfil quanto por seus seguidores e outros usuários para comentar o programa. Essa categoria abrange os tweets enviados pela conta utilizando essa tag. No total, são contabilizadas 136 publicações (Quadro 3).

Quadro 3. Enumeração de dias, tweets e interações geradas na categoria \#MasterChefBR.

\begin{tabular}{|lccc|}
\hline \multicolumn{1}{c}{ Dia } & Tweets & RTS & Favorites \\
\hline 6 de setembro & 3 & 62 & 388 \\
\hline 7 de setembro & 7 & 225 & 1.164 \\
\hline 8 de setembro & 21 & 3.074 & 7.434 \\
\hline 9 de setembro & 16 & 958 & 3.507 \\
\hline 10 de setembro & 10 & 163 & 881 \\
\hline 11 de setembro & 8 & 212 & 968 \\
\hline 12 de setembro & 5 & 194 & 895 \\
\hline 13 de setembro & 6 & 330 & 1.076 \\
\hline
\end{tabular}


Quadro 3. Continuação.

\begin{tabular}{|lccc|}
\hline \multicolumn{1}{r}{ Dia } & Tweets & RTs & Favorites \\
\hline 14 de setembro & 8 & 559 & 1.594 \\
\hline 15 de setembro & 41 & 9.984 & 28.543 \\
\hline 16 de setembro & 11 & 43.189 & 60.426 \\
\hline Total & $\mathbf{1 3 6}$ & $\mathbf{5 8 . 9 5 0}$ & $\mathbf{1 0 5 . 4 0 0}$ \\
\hline
\end{tabular}

Fonte: Dados elaborados pelos autores (2015).

Quanto ao conteúdo dos tweets, pode-se observar que, em sua grande maioria, as publicações tinham por objetivo apenas comentar ou informar sobre o programa, conforme o Quadro 4:

Quadro 4. Quantidade de publicações da categoria \#MasterChefBR e seus objetivos.

\begin{tabular}{|ll|}
\hline \multicolumn{1}{|c|}{ Objetivo } & Quantidade de Tweets \\
\hline Informar/Comentar & 78 \\
\hline Convidar a interagir & 38 \\
\hline Convidar a assistir & 15 \\
\hline Convidar a assistir e interagir & 5 \\
\hline
\end{tabular}

Fonte: Dados elaborados pelos autores (2015).

Avaliando as publicações, nota-se que a intenção do perfil foi divulgar uma imagem de cada participante - Raul, Jiang e Izabel nos bastidores do programa e instigar os usuários e telespectadores a assistirem ao episódio.

\section{Marcas}

Esta categoria inclui os tweets que mencionam marcas através das mentions, que no total somam 85 tweets, 47.747 retweets e 77.708 favorites. O Quadro 5 demonstra a quantidade de tweets enviados e interações geradas por essa categoria em cada um dos dias de análise:

Quadro 5. Enumeração de dias, quantidade de tweets e interações geradas na categoria marcas.

\begin{tabular}{|lccc|}
\hline Dia & Tweets & RTs & Favorites \\
\hline 6 de setembro & 1 & 35 & 163 \\
\hline 7 de setembro & 5 & 193 & 997 \\
\hline 8 de setembro & 20 & 1.993 & 6.252 \\
\hline 9 de setembro & 9 & 772 & 2.865 \\
\hline 10 de setembro & 4 & 107 & 560 \\
\hline 11 de setembro & 4 & 210 & 851 \\
\hline 12 de setembro & 2 & 127 & 426 \\
\hline 13 de setembro & 4 & 219 & 772 \\
\hline 14 de setembro & 5 & 339 & 1.028 \\
\hline 15 de setembro & 25 & 4.219 & 14.519 \\
\hline 16 de setembro & 6 & 39.533 & 49.275 \\
\hline Total & $\mathbf{8 5}$ & $\mathbf{4 7 . 7 4 7}$ & $\mathbf{7 7 . 7 0 8}$ \\
\hline
\end{tabular}

Fonte: Dados elaborados pelos autores (2015). 
Analisando a quantidade de tweets nos quais as marcas foram mencionadas, podemos afirmar que a @BandTV, sendo a emissora onde o programa é reproduzido, foi a marca mais citada, seguida da @TIMBrasil, que anunciou o vencedor do programa. Conforme o Quadro 6:

Quadro 6. Marcas e quantidade de menções na categoria.

\begin{tabular}{|lc|}
\hline \multicolumn{1}{|c|}{ Marca } & Quantidade de menções \\
\hline$@ B a n d T V$ & 38 menções \\
\hline @TIMBrasil & 20 menções \\
\hline @CifLimpadores & 11 menções \\
\hline$@$ KnorrBrasil & 5 menções \\
\hline @familiaibis & 2 menções \\
\hline @HellmannsBrasil & 2 menções \\
\hline @portaldaband & 2 menções \\
\hline @BrahmaCerveja & 1 menção \\
\hline @cafejornal & 1 menção \\
\hline
\end{tabular}

Fonte: Dados elaborados pelos autores (2015).

Sendo a Band TV a emissora que transmite o MasterChef Brasil, é de certa forma natural que seja a marca mais mencionada entre as apresentadas. Sendo assim, para maior aprofundamento desta pesquisa, é ideal desconsiderá-la e tomar como primeira marca mais citada a TIM Brasil, que obteve o segundo maior número de menções.

\section{Tweets que convidam à interação}

A presente seleção compreende as postagens que têm por objetivo gerar interação com os seguidores e fãs do MasterChef. Compreende 67 tweets que geraram, no total, 12.243 retweets e 38.693 favorites (Quadro 7).

Quadro 7. Enumeração de dias, tweets e interações que convida usuários para interações.

\begin{tabular}{|lccc|}
\hline \multicolumn{1}{|c}{ Dia } & Tweets & RTs & Favorites \\
\hline 6 de setembro & 0 & 0 & 0 \\
\hline 7 de setembro & 1 & 50 & 236 \\
\hline 8 de setembro & 19 & 2.274 & 7.076 \\
\hline 9 de setembro & 6 & 801 & 2.739 \\
\hline 10 de setembro & 5 & 105 & 618 \\
\hline 11 de setembro & 0 & 0 & 0 \\
\hline 12 de setembro & 2 & 106 & 397 \\
\hline 13 de setembro & 1 & 36 & 197 \\
\hline 14 de setembro & 4 & 286 & 803 \\
\hline 15 de setembro & 18 & 3.037 & 10.087 \\
\hline 16 de setembro & 2 & 1.401 & $\mathbf{2 6 . 1 0 5}$ \\
\hline Total & $\mathbf{5 8}$ & $\mathbf{8 . 0 9 6}$ & \\
\hline
\end{tabular}

Fonte: Dados elaborados pelos autores (2015).

É importante ressaltar que nem sempre as respostas e interações foram buscadas através de perguntas. O perfil se utilizou também das hashtags para convidar seus fãs a participarem. 


\section{\#MasterChefResponde}

Os tweets citados com esta tag aparecem nesta divisão para análise por constituírem uma forma importante de comunicação do perfil com seu público, por meio de um participante. Estão contempladas 41 postagens, que geraram 8.584 retweets e 16.439 favorites. O \#MasterChefResponde aconteceu após as eliminações no programa. Durante o período estudado, de 6 a 16 de setembro de 2015, a participante eliminada foi Jiang, que teve a oportunidade de responder perguntas a seus fãs e espectadores do programa (Quadro 8).

Quadro 8. Tipos de tweets enviados com a \#MasterChefResponde.

\begin{tabular}{|lccc|}
\hline \multicolumn{1}{|c}{ Tipo de tweet } & Quantidade & RT's & Favorites \\
\hline Perguntas & 35 & 7525 & 12627 \\
\hline Outros & 6 & 1059 & 3714 \\
\hline
\end{tabular}

Fonte: Dados elaborados pelos autores (2015).

Essa categoria mostra que o MasterChef Brasil apresentou uma grande preocupação em se comunicar com os telespectadores. Essa hashtag representou uma forma eficiente de gerar conversação com os usuários do site, visto que gerou diversas perguntas. A partir da análise individual das categorias de publicações, elas foram listadas conforme a quantidade de publicações que continham suas características, em ordem decrescente.

Em um primeiro momento, falaremos sobre a categoria que engloba os tweets com a hashtag \#MasterChefBR. A classificação analisada foi a que gerou mais publicações, interações entre retweets e favorites. Esse tagueamento era utilizado tanto pelo próprio perfil quanto pelos usuários e seguidores. A utilização da hashtag para destacar as postagens relacionadas com o programa foi uma estratégia que trouxe benefícios para o MasterChef, pois possibilitou que os usuários acompanhassem tanto as notícias postadas pelo próprio perfil quanto os comentários postados por outros internautas, incluindo os comentaristas famosos que foram convidados para assistir ao episódio final. Entendemos, também, que seu uso motivou os fãs do perfil a enviarem tweets comentando o programa, pois sabiam que suas publicações teriam a visibilidade de outros participantes e do próprio perfil do MasterChef na rede social. Recuero e Zago (2010) confirmam a funcionalidade dessa função afirmando que seu uso pode promover uma organização das informações e a retomada de discussões. Ou seja, quando um usuário quiser acessar essa hashtag na busca do Twitter, encontrará os comentários feitos utilizando-a.

A categoria \#MasterChefBR suscitou, no total, 58.950 retweets. Sendo essa divisão a que mais gerou esse tipo de interação, torna-se importante validar sua funcionalidade. Os retweets também são formas benéficas de comunicação no Twitter, pois é a funcionalidade que este site de rede social disponibiliza para compartilhamento de informações. Recuero (2012) afirma que essa função permite que as informações circulem entre várias redes sociais. Entendemos que os usuários podem ter várias conexões no site, formadas por grupos de pessoas que compartilham interesses comuns. Ao retweetar uma publicação com a \#MasterChefBR, um indivíduo pode divulgar essa tag para outras redes sociais que se formaram por outro interesse em comum que não o programa, gerando curiosidade para que a pessoa confira à que tagueamento se refere e se interesse pelo seu conteúdo, passando assim a se interessar pelo programa 
e a acompanhar o perfil no Twitter. Zago (2011) também afirma que perfis que possuem mais seguidores exercem uma influência maior, visto que suas publicações atingem mais usuários e, por consequência, mais redes. Com essa afirmação, vemos também como foi benéfica a estratégia utilizada pelo MasterChef quando convidou celebridades da internet para comentarem o programa ao vivo, durante a grande final, utilizando a hashtag à qual esta categoria se refere e conferindo visibilidade a ela.

A análise aponta também que a maioria dos tweets enquadrados nessa divisão tinha por objetivo transmitir informações sobre o programa. Muitas vezes, o perfil utilizou-se de uma comunicação casual, falando como se fosse um dos usuários. Este tipo de comunicação gera maior aceitação pelos usuários e faz que eles se relacionem com o perfil, sintam-se como amigos dele, conectados. Castro (2012) confirma que essa estratégia gera bons resultados, afirmando que é muito importante que as marcas se comportem como pessoas nas redes sociais.

Essa organização de tweets também gerou a maior quantidade de favorites dentre todas as citadas, sendo 105.400. Percebemos, ao avaliar os números apresentados por ela, que a quantidade de favorites é bastante maior do que a de retweets. Esse fato pode ter ocorrido pois, muitas vezes, 0 conteúdo postado agrada os internautas a ponto de curtirem a publicação, porém, eles não a consideram tão importante a ponto de compartilhá-la.

Seguiremos a análise com as considerações sobre a categoria "Participantes”. Em um reality show, os concorrentes são a representação dos telespectadores na televisão. Quando alguém assiste a um programa como o MasterChef, cria uma relação com os concorrentes e escolhe seu favorito, aquele pelo qual torce, com quem sofre e comemora. No período de análise, a participante mais citada pelo perfil foi a chinesa Jiang $\mathrm{Pu}$, eliminada na semifinal. A mesma situação se refletiu no site como um todo. Maia e Flores (2015) apontam que em 8 de setembro, dia da eliminação de Jiang, 45\% dos 551 mil tweets referentes ao MasterChef citavam a chinesa. Uma análise do programa no Twitter feita por Recuero (2015), na semana antes do dia 27 de agosto, utilizando o Gephi, também mostra que Jiang era uma das participantes mais faladas e estava fortemente relacionada aos termos "melhor" e "amo".

A autora também ressalta que as associações com a cozinheira amadora mostraram que sua torcida relacionava seu nome a adjetivos e conceitos positivos. Percebe-se, então, que os telespectadores se sentiam conectados com Jiang de alguma forma e subentende-se que assistiriam ao programa para vê-la cozinhando. Recuero (2009) explica a existência desse laço quando afirma que, no Twitter, é possível formar uma rede de contatos sem haver reciprocidade nas interações. Essa rede de contatos, mesmo sem interações recíprocas, dá a seus autores o acesso a valores que não estariam disponíveis de outra forma. Podemos, também, fazer uma observação sob outro viés. Zago e Silva (2014) afirmam que, no Twitter, o usuário pode conectar-se a amigos e contatos que compartilhem informações que lhe interessam. Quem cria a cultura de uma marca são seus fãs. Essas informações possibilitam o entendimento de que, se o público tinha Jiang como sua participante favorita, o fato de deixá-la em evidência se torna benéfico para o perfil conseguir mais seguidores e mais interações.

Prosseguindo com a investigação, temos as considerações da categoria "marcas”, que compreendeu um total de 85 publicações. Ao investigarmos, percebemos que a @BandTV aparece em evidência. Essa característica pode ter sido pontuada devido ao fato de que a Band é a emissora que transmite a versão brasileira do MasterChef e, desta forma, é importante 
que seja fortemente mencionada e divulgada. Assim, torna-se relevante desconsiderá-la e aprofundar o estudo tendo como primeira marca mais citada a @TIMBrasil.

A empresa aparece em 20 dos 85 tweets enviados que se enquadram na categoria. Um fator que pode explicar o forte investimento da TIM nessa comunicação é o fato de que o setor de telefonia, em 2015, apresentou vários problemas relacionados à sua reputação. De acordo com Haidar (2015), diversos clientes fizeram reclamações sobre as operadoras em geral por terem sua navegação bloqueada ao atingirem o limite de seu pacote de dados. Esse fato a levou a ser notificada pelo Ministério da Justiça por indício de publicidade enganosa, visto que seu plano "TIM WhatsApp ilimitado” não apresentava as informações necessárias aos consumidores. O pacote faria parte de uma promoção com encerramento pré-determinado e este dado não estava sendo divulgado pela operadora. Dessa forma, o investimento em mídias sociais se mostra muito benéfico, pois pode gerar feedback dos clientes, além de proporcionar à marca uma presença em atividades cotidianas destes, como acessar os sites de rede social -atividade que já se tornou muito comum. Assim, cria-se com o usuário uma proximidade, atualmente muito almejada pelas empresas. Neste caso, envolvendo a TIM e o MasterChef, a forma como a marca foi citada tem características de conversação e diálogo.

Além de comunicar-se de uma forma diferenciada e aparecer repetidamente em um programa com uma quantidade significativa de fãs, a comunicação direcionada à TIM foi baseada em relacionamento. Dos vinte tweets que mencionam a empresa, apenas um mostrou trazer conteúdo publicitário. Castro (2012, p. 136) afirma que se percebe em marcas famosas como Apple e Coca-Cola um esforço em construir uma marca que gere identificação e atraia o consumidor para seu universo simbólico. Entendemos, no caso analisado, um uso da comunicação semelhante ao aplicado pelas empresas mencionadas pela autora. Uma das publicações que gerou mais resultados foi aquela em que Izabel Alvares é anunciada campeã do MasterChef (Figura 1).

MasterChef Brasil @masterchefbr-Sep 16

Para tudo! A@TIMBrasil tem a honra de anunciar que o troféu do \#MasterChefBR vai para a Izabel! Parabéns! lo//o/lo/

Vievi translation

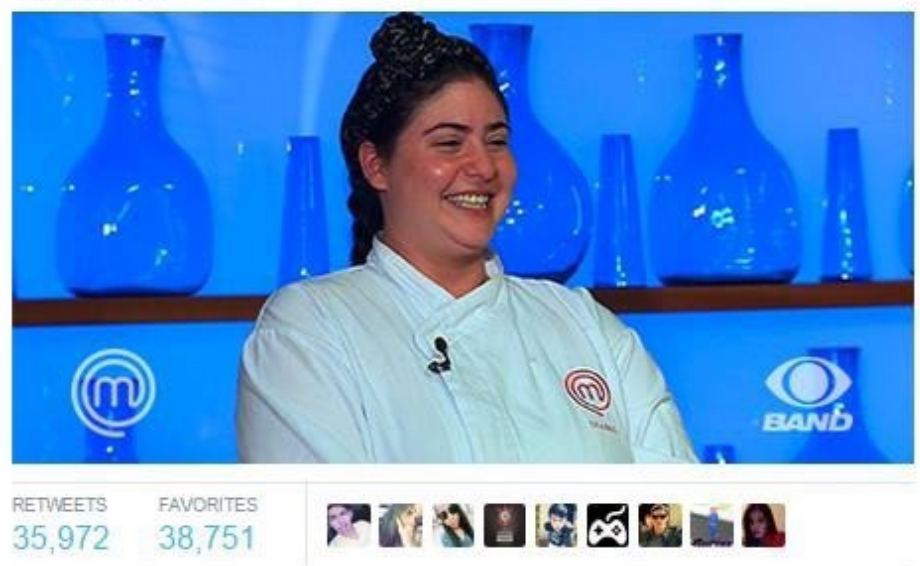

1:11 AM - 16 Sep 2015 . Details

Figura 1. Tweet que anuncia Izabel, a vencedora da competição. 
A estratégia, além de mostrar um excelente uso do Twitter como ferramenta de comunicação, anunciando a resposta no site de rede social antes mesmo de anunciar no programa transmitido pela televisão, trouxe visibilidade para a TIM. Telles (2010, p. 154) confirma que estratégias bem pensadas como essa são fundamentais, afirmando que são elas, acompanhadas do planejamento e do pensamento, que farão a comunicação nas ferramentas funcionar.

O Quadro 1 nos mostrou que a quantidade de publicações e interações se relaciona. Quanto mais postagens se enquadram na categoria, mais interações foram geradas. Entretanto, nas duas últimas classificações, esse padrão se inverte. A divisão \#MasterChefResponde apesar de apresentar 41 publicações - menos do que a categoria composta por tweets que convidam à interação, que correspondem a 58 postagens - trouxe mais retweets: 488 a mais do que a outra categoria. Esse padrão pode ser explicado, pois na categoria mais retweetada estão as respostas deixadas pela participante Jiang aos leitores do perfil. Além de ser a favorita na competição, conforme apresentado anteriormente (RECUERO, 2015), Jiang Pu é chinesa e, apesar de um português muito bem articulado, apresenta pequenas dificuldades na fala e na escrita.

Avaliando as duas categorias como um todo, percebe-se uma grande preocupação do perfil em gerar respostas e interações. Terra (2011) nos mostra como esse tipo de comunicação é importante para as marcas. A autora afirma que o travamento de diálogos e conversações, juntamente com o compartilhamento de conteúdos, é um dos grandes pilares das mídias sociais. Telles (2010, p. 160), por sua vez, concorda e afirma que prestar atenção nas opiniões expostas nas comunidades em comentários, com objetivo de satisfazer necessidades e interagir com usuários, é a base do marketing de relacionamento nas mídias sociais. Terra (2011) ainda explica que, ao atuar no meio digital, as organizações precisam se preocupar com questões como conteúdos interativos, ambientes colaborativos, confiança, atualização e diálogo. A autora também lembra que as mídias sociais são sobre relacionamentos e construção de redes e debates.

\section{CONSIDERAÇÕES FINAIS}

Este estudo possibilitou a verificação da usabilidade do Twitter como ferramenta publicitária para a construção da imagem de marca. A partir do objeto de pesquisa, foram analisadas 218 publicações em um período de 11 dias, de 6 a 16 de setembro de 2015, cujos conteúdos foram categorizados e analisados conforme suas características. Além das cinco categorias do construto, foi investigada a quantidade de interações geradas por elas.

Inicialmente observamos o levantamento e a categorização do conteúdo publicado pelo MasterChef Brasil no período de pesquisa. 0 levantamento foi realizado totalizando 218 tweets que geraram 77.478 retweets e 154.314 favorites. Essas publicações, por sua vez, foram categorizadas, resultando em cinco divisões: Marcas, Participantes, MasterChefBR, MasterChefResponde e Convite à interação. Essas categorias permitiram a execução da análise que permeia este estudo e a realização dos demais objetivos apresentados.

O segundo objetivo se referiu à compreensão dos aspectos motivacionais de comunicação das empresas no Twitter. Por meio da categorização e análise, percebemos diversos fatores que 
levam as empresas a se comunicarem com seus clientes através do microblog: criação de identidade para a marca, divulgação, criação de relacionamento com os fãs, motivação de clientes a comentar positivamente, interação com os usuários do site.

O terceiro objetivo pôde ser comprovado ao analisar o uso do microblog Twitter como ferramenta de interação entre marcas e fãs em tempo real, e assim concluímos sua crescente eficiência. Na noite da final, a hashtag MasterChef Brasil gerou mais de 1,8 milhão de interações, o que comprova que o perfil utilizou-se muito bem desta ferramenta para a comunicação. Além disso, percebemos que o MasterChef Brasil proporcionou uma experiência nova aos usuários e telespectadores ao anunciar o vencedor da competição em primeira mão no Twitter. Essa atitude fez com que a ferramenta fosse vista com mais credibilidade. $\mathrm{O}$ tweet em questão, por sua vez, resultou em uma interação jamais vista no país e foi comparado diversas vezes com a ação da Samsung no Oscar, ao criar a maior selfie de todos os tempos.

O objetivo geral deste trabalho de conclusão consistiu em avaliar a eficiência do Twitter como ferramenta criadora da imagem de marca através do estudo de caso do perfil do MasterChef. Concluímos, analisando os dados expostos, que a ferramenta pode ser muito benéfica para estes fins, pois viabiliza várias formas de inserção das marcas no universo dos fãs, criando diálogos, relacionamentos e gerando feedbacks por parte dos clientes, além, é claro, de tornar possível a divulgação de uma marca, serviço ou empresa.

Recomendam-se, para pesquisas posteriores, que sejam avaliados todos os tweets enviados pela conta, pois possibilitariam um estudo ainda mais completo das táticas utilizadas. Outra pesquisa interessante cruzaria as publicações do perfil MasterChef Brasil com um perfil do exterior, como o MasterChef Austrália, por exemplo. Dessa forma, o pesquisador poderia compreender o objetivo não só do Brasil, mas de outros países ao utilizar o Twitter para comunicação de marca.

\section{REFERÊNCIAS}

ARRUDA, G. As novas tecnologias e as novas pessoas. Meio \& Mensagem: Proxxima, São Paulo, 2015. Disponível em: <https://goo.gl/p6Z1es>. Acesso em: 17 out. 2015.

CASTRO, G. G. S. Entretenimento, sociabilidade e consumo nas redes sociais: cativando o consumidor-fã. Revista Fronteiras: Estudos Midiáticos, São Leopoldo, v. 14, n. 2, p. 133-140, mai./ago. 2012. Disponível em: <https://goo.gl/KNvKer>. Acesso em: 22 out. 2015.

DALMONTE, E. F. Novos cenários comunicacionais no contexto das mídias interativas: o espalhamento midiático. Revista Famecos: Mídia, Cultura e Tecnologia, Porto Alegre, v. 22, n. 2, p. 99-114, 2015

HAIDAR, D. Operadoras de celular bloqueiam internet quando pacote atinge limite. Jornal Hoje, Rio de Janeiro, 24 fev. 2015. Disponível em: <https://goo.gl/bwNtX3>. Acesso em: 13 out. 2015

KIM, J.; LEE, Y. O.; PARK, H. W. Delineating the complex use of a political podcast in South Korea by hybrid web indicators: the case of the Nakkomsu Twitter network. Technological Forecasting and Social Change, Amsterdam, v. 110, p. 42-50, 2015.

LARANGEIRA, A. N.; CARDOSO, M.; KUMM, A. A. Interações temporais na era da convergência: perspectivas das gerações $Y$ e $Z$ nas redes sociais digitais. Educação, Cultura e Comunicação, São Paulo, v. 7, n. 14, p. 139-153, 2016.

NUNOMURA, E. A imprensa, o Twitter e as eleições de 2010 no Brasil. Intercom: Revista Brasileira de Ciências da Comunicação, São Paulo, v. 36, n. 1, p. 103-126, 2013. 
RECUERO, R. A rede é mensagem: efeitos da difusão de informações nos sites de rede social. Raquel Recuero: Artigos Publicados, Pelotas, 2012. Disponível em: <https://goo.gl/ is3N1M>. Acesso em: 13 out. 2015.

\#MasterChefBrasil: dados da última semana no Twitter. Raquel Recuero: Artigos Publicados, Pelotas, 2015. Disponível em: <https://goo.gl/Sf6yXD>. Acesso em: 11 nov. 2015. Redes sociais na internet. Porto Alegre: Sulina, 2009.

RECUERO, R.; ZAGO, G. "RT, por favor": considerações sobre a difusão de informações no Twitter. Revista Fronteiras, São Leopoldo, v. 12, n. 2, p. 69-81, 2010.

TELLES, A. A revolução das mídias sociais: cases, conceitos, dicas e ferramentas. São Paulo: M.Books, 2010.

TERRA, C. F. O que as organizações precisam fazer para serem bem vistas nas mídias sociais sob a ótica da comunicação organizacional e das relações públicas. In: CONGRESSO ABRAPCORP, 5., 2011, São Paulo. Anais... São Paulo: Abrapcorp, 2011. Disponível em: <https://goo.gl/D1ZxYB>. Acesso em: 11 nov. 2015.

ZAGO, G. S.; SILVA, A. L. M. Sites de rede social e economia da atenção: circulação e consumo de informações no Facebook e no Twitter. Vozes e Diálogo, Itajaí, v. 13, n. 1, p. 5-17, 2014.

ZAGO, G. S. Informações jornalísticas no Twitter: redes sociais e filtros de informações. Comunicologia: Revista de Comunicação da Universidade Católica de Brasília, Brasília, v. 4, n. 1, p. 58-73, 2011. Disponível em: <https://goo.gl/ZHtwVo>. Acesso em: 16 out. 2015. 